\title{
Primacy effects in animal memory and human nonverbal memory
}

\author{
ANTHONY A. WRIGHT \\ University of Texas Health Science Center, Graduate School of Biomedical Sciences, Houston, Texas
}

\begin{abstract}
Evidence for primacy effects in animals' list memory is accumulating, despite assertions that these primacy effects may be list-initiation-response artifacts (D. Gaffan, 1983; E. Gaffan, 1992). This evidence comes from list-memory experiments with pigeons and monkeys in which primacy changed with retention interval, experiments with monkeys in which primacy correlated with list length, and experiments with monkeys in which there were no list-initiation responses. Furthermore, there is growing evidence that animal memory is similar to, at least, the nonverbal part of human memory. This evidence comes from human nonverbal-memory experiments in which primacy changed with retention interval (similar to animals) when using kaleidoscope or snowflake stimuli, and similar experiments in which the verbal/nonverbal component was manipulated. Conditions conducive for obtaining primacy effects are discussed.
\end{abstract}

An issue of central importance in comparative cognition is the degree of similarity between animal and human memory processing. One way to relate animal and human memory processes is through a comparison of serial-position functions. Primacy and recency effects (superior memory for the first few and last few items of a memory list, respectively) of the human serial-position function form a considerable body of evidence implicating human memory processes. Primacy effects and recency effects from many tasks are considered to index aspects of long- and short-term memory, respectively, and dissociations of them are generally interpreted as evidence for dual memory processes in humans (e.g., Crowder, 1976; Tulving, 1987).

The issue of similar memory processing between animals and humans has, among other things, focused on the following question: Are animals capable of producing primacy effects? Related to this issue is the question: If animals are capable of producing primacy effects, are these effects analogous to human primacy effects? That is, do animal primacy effects behave in the same way that human primacy effects do, by responding to similar variables and showing similar dissociations? Although there has not been total agreement regarding the answers to these questions, the evidence to date suggests affirmative answers to all of these questions, as will be shown in this article.

\footnotetext{
Preparation of this manuscript and the research shown in the figures was supported by NIH Grant R01-35202. I gratefully acknowledge the contributions of Roddy Roediger and Jocelyne Bachevalier for their helpful comments on an earlier manuscript draft, a reviewer, Bill Roberts, for pointing out that the Castro and Larson experiment was biased against finding primacy effects, and Susan Wright for her editorial suggestions. Reprints may be obtained from A. A. Wright, University of Texas Sensory Sciences Center, Suite 316, 6420 Lamar-Fleming Ave., Houston, Texas 77030 .
}

In a recent article, E. Gaffan (1992) questioned the validity of primacy effects shown for rats, pigeons, squirrel monkeys, rhesus monkeys, and chimpanzees. She argued that radial-arm maze experiments with rats have "excessively low variance or . . . unacceptable data selection policies,"' whereas "'in all of the automated experiments [those involving primates or pigeons], an observing response was employed for the initiation of the list, so that these experiments are subject to D. Gaffan's objection (1983) that primacy reflects attentional rather than mnemonic enhancement" (p. 251).

The objection (D. Gaffan, 1983) to which E. Gaffan refers was a response to three articles showing primacy effects for squirrel and rhesus monkeys (Roberts \& Kraemer, 1981; Sands \& Wright, 1980a, 1980b). D. Gaffan (1977c) had not found primacy effects from his rhesus monkeys with three-item memory lists. He dismissed the primacy effects shown by us (as has E. Gaffan) as artifacts of list-initiation responses, and claimed that "its [primacy's] general absence both in human nonverbal memory and in monkeys' memory has been one of the grounds for believing that memory processes and mechanisms in monkeys are analogous to at least the nonverbal part of human memory (Gaffan, 1977a, 1977b, 1977c)'" $(1983$, p. 144).

The purpose of the present article is to show that monkeys, pigeons, and humans, under nonverbal-memory conditions, all produce primacy effects, and that these primacy effects are not the result of artifacts produced by list-initiation responses.

\section{Primacy Effects in Monkey Memory}

It is not clear to me how this objection of D. Gaffan (1983) can apply, as E. Gaffan contends, to results from an experiment of ours in which changes in primacy (and recency) effects were shown for pigeons, monkeys, and 

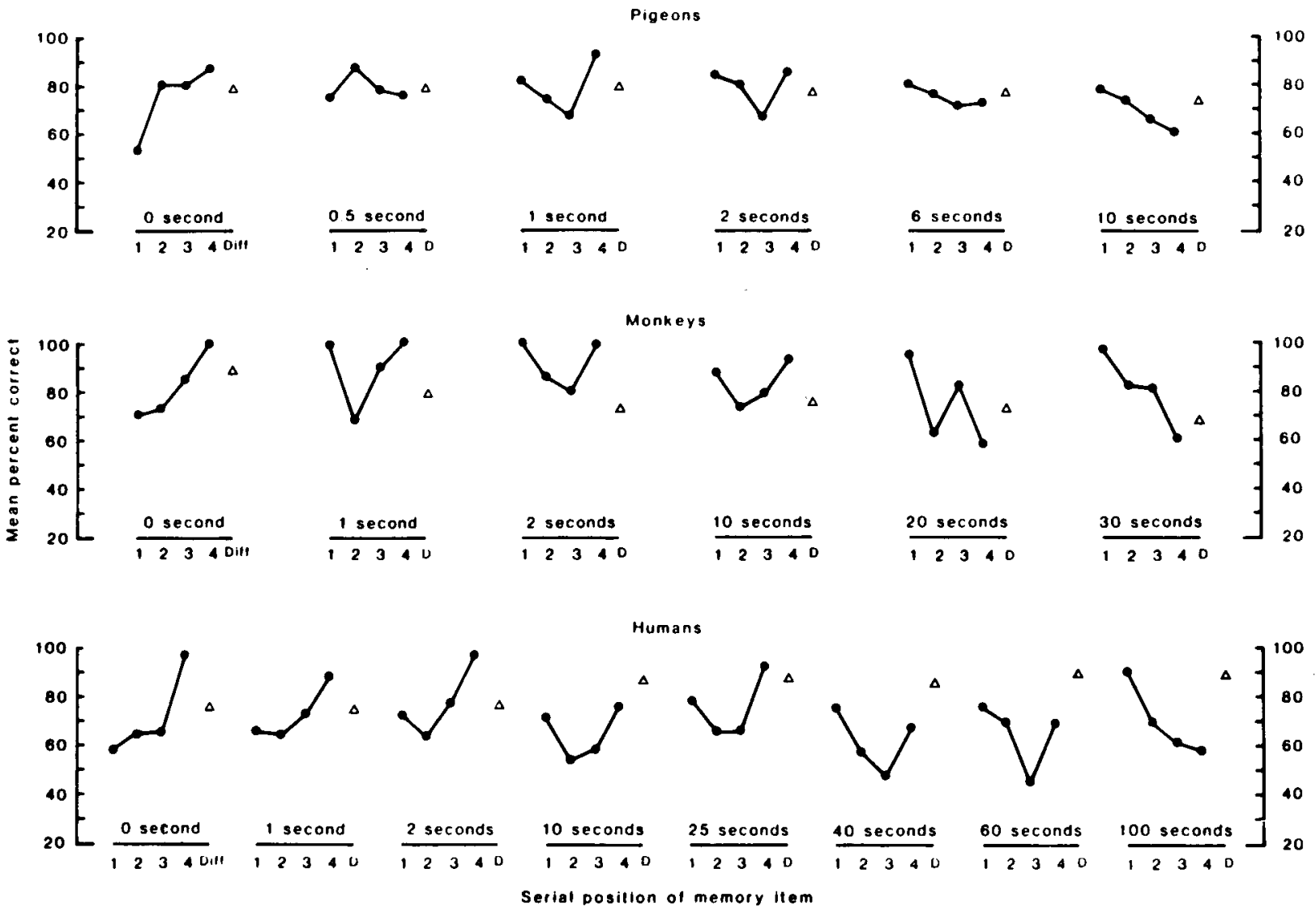

Figure 1. Mean memory performance for four-item lists and different retention intervals, the interval between the last list item (labeled "4"), and the probe test item. Open triangles show performance on different trials, in which the probe item did not match any of the four list items. From "Memory Processing of Serial Lists by Pigeons, Monkeys, and People," by A. A. Wright, H. C. Santiago, S. F. Sands, D. F. Kendrick, and R. G. Cook, 1985, Science, 229, pp. 287-289. Copyright 1985 by American Association for the Advancement of Science. Adapted by permission.

humans (Wright, Santiago, Sands, Kendrick, \& Cook, 1985). In that study, our subjects initiated all memory lists. If primacy effects were an artifact of list-initiation responses, then primacy effects should have appeared in all conditions. But primacy effects were found in some test conditions and not in others, even though the listinitiation response was the same in all conditions. Figure 1 shows the average results for the three species in that four-item list-memory experiment.

In Wright et al. (1985), monkeys and humans initiated memory lists by pushing down on a three-position " $T$ "' lever, and pigeons pecked on a viewing window. Lists of "travel" slides for monkeys and pigeons and lists of kaleidoscope patterns for humans were then presented (via a slide projector) on the upper of two rear projection screens. Memory lists were four items in the experiment (but were 10 and 20 items in some other experiments of ours with monkeys and humans). Following the list, a single probe/test item (via a second slide projector) appeared on the lower screen. The subjects then made a choice response to indicate whether the test item was or was not contained in the memory list. The pigeons pecked one side key for "yes" and another for "no," and the monkeys and humans moved a lever to the right or left. Following an intertrial interval, another memory list (trial) was presented. The parameter of importance in each panel of Figure 1 is the delay between the last (fourth) list item and the probe test item-the retention interval. The leftmost panels for each species show no primacy effects; this is the condition in which the probe test appeared immediately following each four-item list. When there was a delay of but a few seconds, the primacy effect appeared. With further increases in retention interval, the recency effect eventually dropped out, leaving the primacy effect.

If the primacy effect had been an artifact of the listinitiation response, then it should have been present at all delays (because the list-initiation response was the same), and should not have varied with delay. But the primacy effect did vary with delay. Similar serial-positionfunction changes were shown for individual animal subjects comprising the group averages (Santiago \& Wright, 1984; Wright, Santiago, \& Sands, 1984). Furthermore, similar serial-position-function changes were shown for human subjects. This finding contradicts D. Gaffan's (1983) assertion that there is a general absence of primacy effects in human nonverbal memory. 
If the issue here is capability (and I believe that it is), then it seems to me that there can be several, if not many, experimental results showing no primacy effects for animals without proving that animals are incapable of producing them (the null hypothesis). With animals, as with humans, there are probably many ways to disrupt the primacy effect. In addition to the example cited previously, in which the primacy effect was absent with short retention intervals but appeared with longer ones, we also found that primacy effects were absent with short list lengths but were present with longer ones. In this second research example, we found that with 3-item list lengths, the same list length used by D. Gaffan (1977c), we likewise did not find any primacy effects (Sands \& Wright, $1980 \mathrm{~b}$, Experiment 3). But with 10- and 20-item lists (and otherwise the same list-initiation response and stimulus presentation procedures), we found strong, reliable primacy effects (Sands \& Wright, 1980b, Experiments 1 and 2). ${ }^{1}$ This is another contradiction of D. Gaffan's listinitiation hypothesis.

No mention was made of these inconsistencies in either article (D. Gaffan, 1983; E. Gaffan, 1992), even though the experiments of Sands and Wright (1980a, 1980b) had been a target of D. Gaffan's (1983) original criticism. In fact, the three-item-list experiment had been designed from the outset as a replication of D. Gaffan's (1977c) experiment in order to evaluate the effects of proactive interference on performance accuracy (see also Wright, 1990; Wright, Urcuioli, \& Sands, 1986) and make contact with results from an experiment conducted in another laboratory under conditions of high proactive interference (Gaffan, 1977c). In our experiment (Sands \& Wright, 1980b, Experiment 3), high proactive interference lowered performance to $70 \%$ accuracy relative to $93 \%$ correct for low interference. This $70 \%$ accuracy was virtually identical to the performance accuracy obtained by D. Gaffan under similar highproactive-interference conditions. More important, the results also replicated D. Gaffan's finding of no primacy effect. This replication is important, because it shows that results similar to D. Gaffan's were obtained with a monkey that had shown primacy effects with longer lists. Although some experiments have shown primacy effects with threeitem list lengths (e.g., Roberts \& Kraemer, 1981, for squirrel monkeys), in other experimental settings it may be a matter of testing with longer list lengths or longer retention intervals in order for primacy effects to appear.

In the decade since D. Gaffan (1983) introduced the list-initiation hypothesis of the primacy effect, there has not been any evidence (that I know of) to support it. It could have been directly tested with monkeys that do not make list-initiation responses in conditions otherwise similar to those that regularly produce primacy effects. If the results showed primacy effects without list initiations, then this finding would disprove the list-initiation hypothesis of the primacy effect.

Such an experiment has been recently conducted by Castro and Larsen (1992). They used a serial-proberecognition procedure (very similar to the one used by
Sands \& Wright, 1980a, 1980b; Wright et al., 1985), except that their monkeys did not initiate the memory list. Further, to avoid any arguments related to any past history with memory-list-initiation responses, experimentally naive monkeys were used. The monkeys made only choice responses (touching a video monitor) to indicate whether or not a test item was in the list. A probe test item was presented $30 \mathrm{sec}$ following the last item of each list. All 6 rhesus monkeys used in this experiment showed Ushaped serial-position functions with prominent primacy effects (as well as recency effects). This finding of prominent primacy effects is particularly noteworthy because, if anything, this study was biased against finding primacy effects. The monkeys did not have any warning as to when the memory lists would begin. In some cases, they may have been looking away from the screen when the first item was presented; consequently, they may have had less exposure to the first item than to succeeding items in the list. The superior memory for first list items (primacy effect) under these conditions is direct, compelling evidence that primacy effects in monkeys are not artifacts of any list-initiation response, as hypothesized by D. Gaffan (1983) and reiterated by E. Gaffan (1992).

\section{Primacy Effects in Human Nonverbal Memory}

D. Gaffan asserted that the lack of primacy effects in human nonverbal memory and monkey memory was one reason to believe that the underlying memorial processes were similar in these two cases. D. Gaffan has not been alone in his assertion that nonverbal human memory should show a general absence of primacy effects. Over much of the past 25 years, the primacy effect has been inextricably tied to human verbal memory and rehearsal (see earlier theoretical articles, e.g., Atkinson \& Shiffrin, 1968; Waugh \& Norman, 1965, and later continuations of this theme, e.g., Modigliani \& Hedges, 1987). According to what has been called the modal model of the primacy effect, rehearsal moves memory of the items from short-term to long-term memory, thereby producing the primacy effect. From this hypothetical model, it seems to follow in logical sequence that, because humans as a species have a monopoly on language, and rehearsal is generally accepted to depend upon language, then humans may have a monopoly on the primacy effect as well.

But even research on human memory shows that, although rehearsal may improve memory, primacy effects can be produced in the absence of rehearsal. Consider the results from humans shown in Figure 1. The humans were shown lists of kaleidoscope patterns to remember. Kaleidoscope patterns are extremely difficult for humans to verbalize (code/label) and, consequently, to rehearse. Furthermore, these particular kaleidoscope patterns were changed regularly. So, if the humans could not code or label them, how could they rehearse them? If they could not rehearse them, then, according to the theory, they should not have shown primacy effects. But, like the pigeons and monkeys, the humans did show welldeveloped primacy effects as the retention interval in- 
creased. The point here is that the pattern of changes of the serial-position function, and of the primacy effect in particular, was similar for the three species even though the range of retention intervals over which these changes occurred was different. These similar changes with retention interval argue for similar memorial processes' being responsible for primacy effects (and recency effects) in pigeons, monkeys, and humans.

Additional experiments have shown similar effects and arrived at similar conclusions. Neath (1993) used a wide variety of snowflake patterns, which, like kaleidoscope patterns, humans cannot reliably label. Here, too, performance undoubtedly depended upon nonverbal memory. Lists of four snowflake patterns were presented to the subjects on a computer screen; the list commenced without subject initiation. Following the list, the subjects used computer mouse buttons to indicate whether or not a probe item was in the list. Like Wright et al.'s (1985) experiment, Neath showed no primacy effects for the zeroretention-interval condition. Also similar to Wright et al., primacy effects developed with longer retention intervals. Indications of a similar rise in the primacy effect with retention interval can also be seen in a location-recall experiment by Ellis and Hope (1968).

In another experiment, nonverbal versus verbal memory was manipulated with the same set of kaleidoscope stimuli (Wright et al., 1990). Some groups of subjects were taught names for 32 kaleidoscope patterns; other groups were prevented from learning names for the same patterns by engaging them in distracting familiarization tasks. All the subjects were interviewed about their memory strategies with particular attention to verbal labeling and rehearsal. Another measure of subjects' rehearsal was an effect of interitem or interstimulus interval (ISI). Typically, subjects in this type of experiment perform as well with brief stimuli (pictures) as with prolonged stimuli, pro- vided that "blank" time (ISI) makes up the time difference. When the ISI decreases, performance decreases (e.g., Intraub, 1980). The evidence suggested that subjects use the ISI to rehearse and thereby improve their memory performance (e.g., Proctor, 1983).

Figure 2 shows serial-position functions from subjects who did not verbally label or rehearse the stimuli, as shown through interviews and lack of improved memory performance with longer interitem intervals (see Wright et al., 1990, Figure 6). These subjects, nevertheless, showed pronounced primacy effects. Notice, in the lefthand panel, that even when all six list items were presented in less than $1 \mathrm{sec}(0.08$-sec viewing time and ISI), there was still a prominent primacy effect.

Few would question that rehearsal in verbal-memory experiments improves retention. But it does appear that rehearsal and verbal memory are not necessary to produce primacy effects. Indeed, a good way to explore and dissociate the variables responsible for primacy and recency effects may be to manipulate the retention interval in nonverbal-memory tasks (see Figure 1).

\section{Concluding Statements}

The degree of similarity between memory in monkeys and nonverbal memory in humans still remains somewhat of an open question. But it is clear that there are some important basic similarities. Ironically, it is the presence of primacy effects in both species, not its general absence (as the Gaffans have claimed), that provides part of the basis for affirming similar processes in monkey memory and human nonverbal memory. Humans and monkeys showed similar primacy-effect changes with retention interval, and similar dissociations of the primacy effect with the recency effect. This common pattern of performance provides further basis for affirming similar memory processing in humans and monkeys.
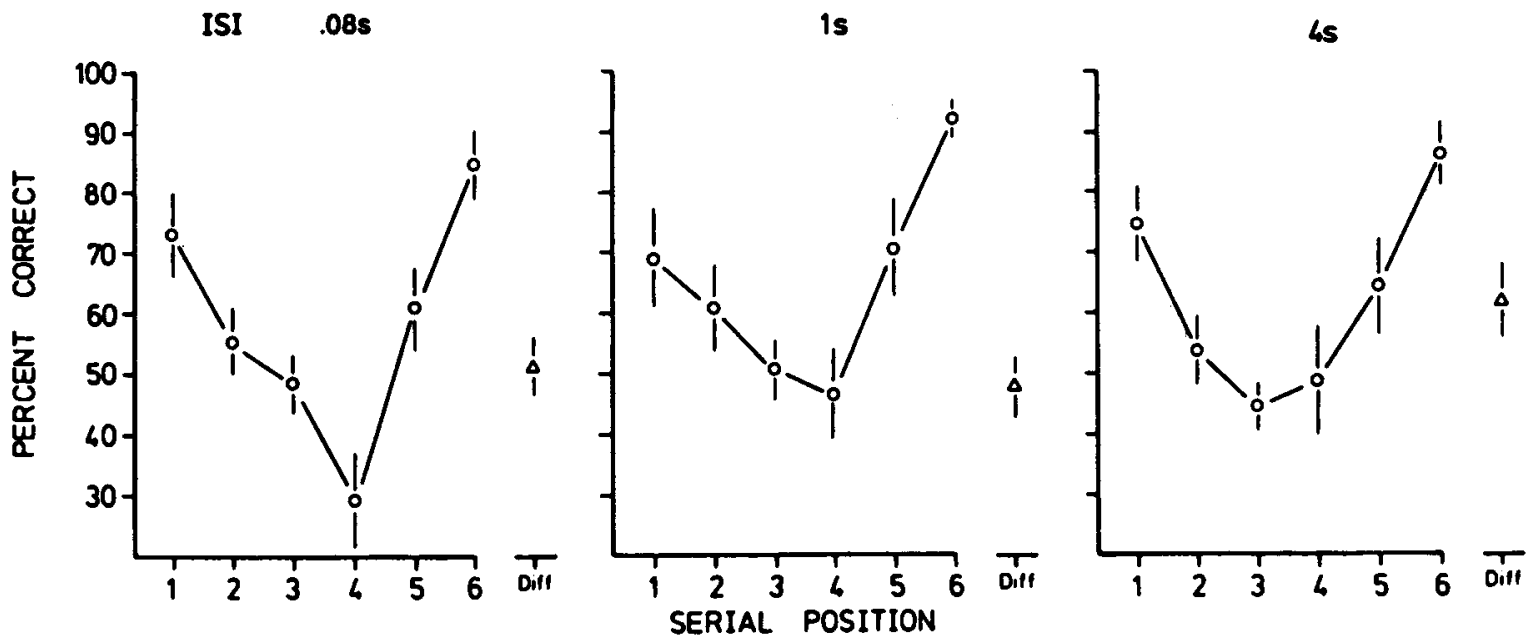

Figure 2. Performance as a function of serial positions for three interstimulus intervals of $0.08,1.0$, and $4.0 \mathrm{sec}$ with a 0.08 -sec viewing time. Open triangles show performance on different trials, in which the probe item did not match any of the six list items. Error bars are standard errors of the mean. Adapted from "Naming, Rehearsal, and Interstimulus Interval Effects in Memory Processing," by A. A. Wright et al., 1990, Journal of Experimental Psychology: Learning, Memory \& Cognition, 16, $1043-1059$. Copyright 1990 by the American Psychological Association. Adapted by permission. 
The dynamic nature of the primacy effect may help to explain why the controversy over primacy effects (in human nonverbal memory as well as animal memory) ever arose in the first place. The retention-interval experiments showed that the U-shaped serial-position function is only a transitional function between an all-recency and an allprimacy function, not the benchmark function that it has been thought to be for more than a century. This dynamic nature of the primacy effect can lead to wrong conclusions if only one retention interval is tested. For example, if, in the three-species retention-interval experiment (Figure 1), only a 10-sec retention interval had been tested, the conclusion would have been that pigeons do not have a recency effect and primates have primacy and recency effects. On the other hand, if only a 1-sec retention interval had been tested, the conclusion would have been that humans do not have a primacy effect and that pigeons and monkeys have primacy and recency effects. I know of no way to overcome this difficulty, except to generate a whole set of serial-position functions covering a considerable range of retention intervals-a parametric variation of retention interval. Clearly, the time course of these serial-position-function changes depends upon species, and probably upon the task as well, including (1) the type of memory stimuli (pictures, geometric shapes, real objects, etc.), (2) the nature of the memory test (two test stimuli in matching-to-sample, one test stimulus in same/different, etc.), and (3) the type of memory tested (visual, auditory, location, etc.). The bottom line is that many species in many memory tasks can probably be shown to produce primacy effects if experimenters shape the task requirements to capitalize upon the species' natural predispositions and systematically vary parameters (e.g., list length, retention interval, etc.) to allow an opportunity for primacy effects to appear.

\section{REFERENCES}

Atkinson, R. C., \& Shiffrin, R. M. (1968). Human memory: A proposed system and its control processes. In K. W. Spence \& J. T. Spence (Eds.), The psychology of learning and motivation (Vol. 2, pp. 89-105). New York: Academic Press.

Castro, C. A., \& Larsen, T. (1992). Primacy and recency effects in nonhuman primates. Journal of Experimental Psychology: Animal Behavior Processes, 18, 335-340.

CROWDer, R. G. (1976). Principles of learning and memory. Hillsdale, NJ: Erlbaum.

ElLIS, N. R., \& HoPE, R. (1968). Memory processes and the serial position curve. Journal of Experimental Psychology, 77, 613-619.

GAFFAN, D. (1977a). Exhaustive memory-scanning and familiarity discrimination: Separate mechanisms in recognition memory tasks. Quarterly Journal of Experimental Psychology, 29, 451-460.

GAFFAN, D. (1977b). Monkeys' recognition memory for complex pictures and the effect of fornix transection. Quarterly Joumal of Experimental Psychology, 29, 505-514.

GAFFAN, D. (1977c). Recognition memory after short retention intervals in fornix-transected monkeys. Quarterly Journal of Experimental Psychology, 29, 577-588.

GAFFAN, D. (1983). A comment on primacy effects in monkeys' memory for lists. Animal Learning \& Behavior, 11, 144-145.
Gaffan, E. A. (1992). Primacy, recency, and the variability of data in studies of animals' working memory. Animal Learning \& Behavior, $20,240-252$.

INTRAUB, H. (1980). Presentation rate and the representation of briefly glimpsed pictures in memory. Journal of Experimental Psychology: Human Learning \& Memory, 6, 1-12.

Modigliani, V., \& Hedges, D. G. (1987). Distributed rehearsals and the primacy effect in single-trial free recall. Journal of Experimental Psychology: Learning, Memory, \& Cognition, 13, 426-436.

Neath, I. (1993). Distinctiveness and serial position effects in recognition. Memory \& Cognition, 21, 689-698.

Proctor, R. W. (1983). Recognition memory for pictures as a function of poststimulus interval: An empirical clarification of existing literature. Journal of Experimental Psychology: Learning, Memory, \& Cognition, 9, 256-262.

Roberts, W. A., \& Kraemer, P. J. (1981). Recognition memory for lists of visual stimuli in monkeys and humans. Animal Learning \& Behavior, 9, 587-594.

SANDS, S. F., \& WRIGHT, A. A. (1980a). Primate memory: Retention of serial list items by a rhesus monkey. Science, 209, 938-940.

SANDS, S. F., \& WRIGHT, A. A. (1980b). Serial probe recognition performance by a rhesus monkey and a human with 10 - and 20 -item lists. Journal of Experimental Psychology: Animal Behavior Processes, 6, 386-396.

Santiago, H. C., \& WRight, A. A. (1984). Pigeon memory: Same/different concept learning, serial probe recognition acquisition and probe delay effects on the serial-position function. Joumal of Experimental Psychology: Animal Behavior Processes, 10, 498-512.

TULVING, E. (1987). Introduction: Multiple memory systems and consciousness. Human Neurobiology, 6, 67-80.

Waugh, N. C., \& Norman, D. A. (1965). Primacy memory. Psychological Review, 72, 89-104.

WrIGHT, A. A. (1990). Memory processing by pigeons, monkeys, and people. In G. H. Bower (Ed.), The psychology of learning and motivation (Vol. 23, pp. 25-70). New York: Academic Press.

Wright, A. A., Cook, R. G., Rivera, J. J., Shyan, M. R., Nerworth, J. J., \& JrTsumori, M. (1990). Naming, rehearsal, and interstimulus interval effects in memory processing. Journal of $E x-$ perimental Psychology: Learning, Memory, \& Cognition, 16, 10431059.

Wright, A. A., Santiago, H. C., \& Sands, S. F. (1984). Monkey memory: Same/different concept learning, serial probe acquisition, and probe delay effects. Journal of Experimental Psychology: Animal Behavior Processes, 10, 513-529.

Wright, A. A., Santiago, H. C., Sands, S. F., Kendrick, D. F., \& Cook, R. G. (1985). Memory processing of serial lists by pigeons, monkeys, and people. Science, 229, 287-289.

Wright, A. A., Urcuioli, P. J., SAnds, S. F. (1986). Proactive interference in animal memory research. In D. F. Kendrick, M. Rilling, \& R. Denny (Eds.), Theories of animal memory (pp. 101-125). Hillsdale, NJ: Erlbaum.

\section{NOTE}

1. Because there has been considerable focus on variability measures related to serial-position functions, it seems worthwhile to call readers' attention to the very large number of trials conducted in some of these list-memory experiments with monkeys. For example, in the 10-item experiment (Sands \& Wright, 1980a, 1980b), each of the 10 serial positions was based upon performance from 844 separate, 10-item memory trials. This number of trials imparts extreme reliability to these serialposition performance differences and the primacy effect. The experiment does, however, become lengthy; because the probe item matches a list item on only half of the trials, 16,880 trials were conducted to produce that 10 -item, serial-position function.

(Manuscript received May 8, 1993; revision accepted for publication September 14, 1993.) 